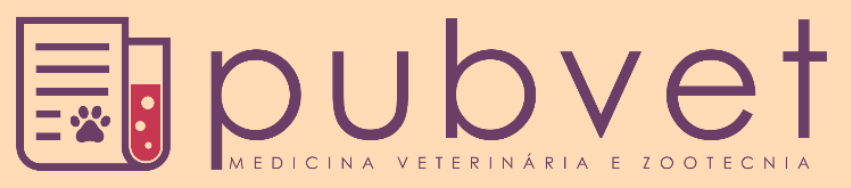

https://doi.org/10.31533/pubvet.v13n12a479.1-10

\title{
Plantas tóxicas de interesse pecuário em municípios da microrregião do Alto Médio Gurguéia - Piauí
}

\begin{abstract}
Caike Pinho de Sousa $^{1 *} \bullet$, Wenderson Rodrigues de Amorim ${ }^{1} \bullet$, Gabriel do Nascimento Martins ${ }^{1} \bullet$, Alan

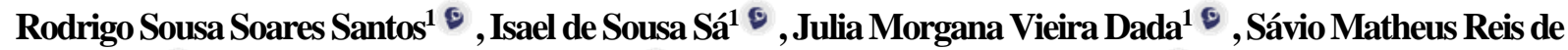
Carvalho $^{1 \oplus}$, Mayara Jane Martins Alves ${ }^{1}{ }^{\ominus}$, Italo Carlos Rodrigues da Silva ${ }^{1}{ }^{\ominus}$, Jackson Brendo Gomes

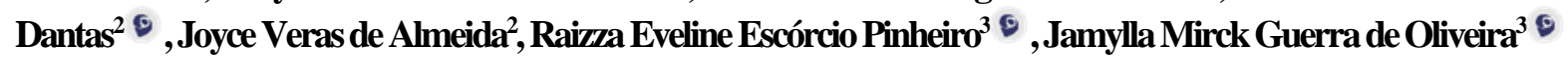

${ }^{1}$ Graduado(a) em Medicina Veterinária, Universidade Federal do Piauí, Bom Jesus, Piauí, Brasil. ${ }^{2}$ Graduando(a) em Medicina Veterinária, Universidade Federal do Piauí, Bom Jesus, Piauí, Brasil.

${ }^{3}$ Docente da Universidade Federal do Piauí, Departamento de Medicina Veterinária, Bom Jesus-PI, Brasil.

*Autor para correspondência. E-mail: caikeufpi@gmail.com

\begin{abstract}
Resumo. Este trabalho teve como objetivo realizar um levantamento das principais plantas tóxicas de interesse pecuário em municípios da Microrregião do Alto Médio Gurguéia, Estado do Piauí, Brasil. Foram realizadas visitas a propriedades, a agências de assistência aos produtores rurais (Agência de Defesa Agropecuária do Piauí - ADAPI e Instituto de Assistência Técnica e Extensão Rural do Piauí - EMATER) e a Instituições de Ensino (Campus Professora Cinobelina Elvas - CPCE e Colégio Técnico de Bom Jesus - CTBJ, ambas vinculadas a Universidade Federal do Piauí - UFPI) durante os meses de maio e junho de 2017. Foram utilizados formulários adaptados para realização das entrevistas. O total de entrevistados foram 60 pessoas, que residiam ou prestavam assistência técnica na região. A amostragem abrangeu nove municípios da microrregião do Alto Médio Gurguéia. Todas as plantas listadas no formulário foram citadas pelo menos uma vez pelos entrevistados, no entanto, foram priorizadas as mais mencionadas. Plantas como Manihot spp. 78,3\%, S. coriaceum 55\%, Brachiaria spp. 43,3\%, E. contortisiliquum 41,7\%, $M$. pseudoglaziovii $25 \%$, D. mollisBenth $14,3 \%$, M. indica $7,1 \%$ e D. ecastophyllum $7,1 \%$ foram apresentadas como tóxicas na região. Resultados semelhantes foram encontrados em municípios pertencentes à microrregião do Cariri, Estado do Ceará. Pode-se concluir que as plantas com potencial tóxico na microrregião do Alto Médio Gurguéia é a planta Manihot spp. 78,3\%, seguida pelas plantas S. coriaceum 55\%, Brachiaria spp. 43,3\%, E. contortisiliquum 41,7\%, M. pseudoglaziovii $25 \%$, D. mollisBenth $14,3 \%$, M. indica 7,1\% e também a planta denominada de D. ecastophyllum $7,1 \%$.
\end{abstract}

Palavras chave: Intoxicação, produção animal, sul piauiense

\section{Toxic plants of livestock interest in municipalities of the microregion of Alto Médio Gurguéia - Piauí}

\footnotetext{
Abstract. This study aimed to conduct a survey of the main toxic plants of livestock interest in municipalities of the microregion of the Alto Médio Gurguéia, state of Piauí, Brazil. Visits were made to farms, to assistance agencies to rural producers (Agência de Defesa Agropecuária do Piauí - ADAPI and Instituto de Assistência Técnica e Extensão Rural do Piauí - EMATER) and Educational Institutions (Campus Professora Cinobelina Elvas CPCE and Colégio Técnico de Bom Jesus - CTBJ, both linked to Universidade Federal do Piauí - UFPI) during the months of May and June 2017. Forms adapted for conducting the interviews were used. The total number of interviewees was 60 people, who resided or provided technical assistance in the region. The sample comprised nine municipalities in
} 
the microregion of the Alto Médio Gurguéia. All the plants listed in the form were cited at least once by the interviewees; however, the most mentioned ones were prioritized. Plants like Manihot spp. 78,3\%, S. coriaceum 55\%, Brachiaria spp. 43,3\%, E. contortisiliquum 41,7\%, M. pseudoglaziovii 25\%, D. mollis Benth 14,3\%, M. indica 7,1\% e D. ecastophyllum $7,1 \%$ were presented as toxic in the region. Similar results were found in municipalities belonging to the micro region of the Cariri, state of Ceará. It can be concluded that plants with toxic potential in the microregion of the Alto Médio Gurguéia is the plant Manihot spp. 78,3\%, followed by the plants S. coriaceum 55\%, Brachiaria spp. 43,3\%, E. contortisiliquum 41,7\%, M. pseudoglaziovii 25\%, D. mollis Benth 14,3\%, M. indica $7,1 \%$ and also the plant called D. ecastophyllum $7,1 \%$.

Keywords: Intoxication, animal production, South Piauí

\section{Plantas tóxicas de interés ganadero en municipios de la microregión de Alto Médio Gurguéia - Piauí}

Resumen. Este estudio tuvo como objetivo realizar un estudio de las principales plantas tóxicas de interés ganadero en municipios de la microrregión de Alto Médio Gurguéia, estado de Piauí, Brasil. Se realizaron visitas a fincas, a los organismos de asistencia a los productores (Agência de Defesa Agropecuária do Piauí - ADAPI y Instituto de Assistência Técnica e Extensão Rural do Piauí - EMATER) y a Instituciones Educativas (Campus Professora Cinobelina Elvas - CPCE y Colégio Técnico de Bom Jesus - CTBJ, ambos vinculados a la Universidade Federal do Piauí - UFPI) durante los meses de mayo y junio de 2017. Se utilizaron formularios adaptados para la realización de las entrevistas. El número total de entrevistados fue de 60 personas, que residían o prestaban asistencia técnica en la región. La muestra comprendía nueve municipios de la microrregión del Alto Médio Gurguéia. Todas las plantas enumeradas en el formulario fueron citadas al menos una vez por los entrevistados, sin embargo, se priorizaron las más mencionadas. Plantas como Manihot spp. 78,3\%, S. coriaceum 55\%, Brachiaria spp. 43,3\%, E. contortisiliquum 41,7\%, M. pseudoglaziovii 25\%, D. mollis Benth 14,3\%, M. indica 7,1\% e D. ecastophyllum $7,1 \%$ se presentaron como tóxicos en la región. Se encontraron resultados similares en municipios pertenecientes a la microregión de Cariri, estado de Ceará. Se puede concluir que las plantas con potencial tóxico en la microregión de Alto Médio Gurguéia es la planta Manihot spp. 78,3\%, seguido por las plantas S. coriaceum 55\%, Brachiaria spp. 43,3\%, E. contortisiliquum 41,7\%, M. pseudoglaziovii 25\%, D. mollis Benth 14,3\%, M. indica 7,1\% y también la planta llamada D. ecastophyllum 7,1\%.

Palabras clave: Intoxicación, producción animal, sur del Piauí

\section{Introdução}

É notável o aumento do interesse pelo estudo da toxicidade de plantas em todo mundo, inclusive no Brasil, que hoje se caracteriza como um dos maiores produtores de produtos de origem animal, como por exemplo, a carne bovina. Segundo dados do Ministério da Agricultura, Pecuária e Abastecimento MAPA, entre os meses de janeiro e maio de 2017 foram abatidos 8.583 .436 bovinos em todo país e segundo a Associação Brasileira das Indústrias Exportadoras de Carnes - ABIEC e ANUALPEC, entre os meses de janeiro e março do mesmo ano foram exportadas 3.416.40 toneladas do produto (ABIEC, 2019; ANUALPEC, 2019). Diante de tais proporções, entende-se a importância de se conhecer as plantas que compõem as pastagens desses sistemas de produção, principalmente devido ao fato de a maioria destas plantas fazerem parte da base alimentar destes animais quando criados em sistema extensivo (Haraguchi, 2003; Magalhães et al., 2013; Tokarnia \& Döbereiner, 2000; Tokarnia \& Dobereiner, 1979).

Atualmente, no Brasil são conhecidas por volta de 130 plantas que possuem potencial tóxico e de interesse pecuário (Sant'Ana et al., 2014; Tokarnia \& Döbereiner, 2000). No entanto, apesar da vasta quantidade de estudos desenvolvidos sobre este tema e a ampla literatura sobre as plantas tóxicas no país, ainda há uma carência de informações quando se refere à frequência de intoxicações causadas por 
plantas em algumas regiões do país (Sousa et al., 2014), como é o caso do Estado do Piauí, que hoje se destaca na produção de caprinos e ovinos, possuindo um setor avícola consolidado e um rebanho bovino próximo de 1.700 .000 cabeças de gado (ADAPI, 2012). Todavia, apresenta poucos trabalhos relacionados a levantamentos das principais plantas tóxicas encontrados na região, principalmente no que se refere à região Sul do Estado.

Uma forma prática e eficaz de caracterização destas plantas é a realização de estudos sistemáticos por meio de pesquisas de campo, pois aumenta consideravelmente o número de espécies tóxicas conhecidas naquela região, facilitando assim o seu manejo. Além do mais, tais dados podem ser divulgados entre médicos veterinários, acadêmicos da área, profissionais que trabalham no campo e produtores, facilitando assim, o controle e atuação desses profissionais, diminuindo a incidência de casos de intoxicação por plantas (Silva et al., 2006; Tokarnia \& Döbereiner, 2000).

Dentre as hipóteses que norteiam este trabalho, acredita-se que devido ao fato de a grande maioria da pecuária da região ser originária do sistema extensivo, as plantas tóxicas presentes nas pastagens é um entrave para a pecuária local (Haraguchi, 2003).

Este trabalho teve como objetivo realizar um levantamento das principais plantas causadoras de intoxicações em animais de interesse pecuário em municípios da Microrregião do Alto Médio Gurguéia, Estado do Piauí, Brasil.

\section{Material e métodos}

O presente trabalho foi realizado nos meses de maio e junho de 2017 com uma amostragem de nove municípios da microrregião do Alto Médio Gurguéia (Bom Jesus, Currais, Santa Luz, Cristino Castro, Palmeira do Piauí, Redenção do Gurguéia, Gilbués, Alvorada do Gurguéia e Barreiras do Piauí). Essa microrregião é pertencente à mesorregião Sudoeste Piauiense. Com uma população de 88.076 habitantes, está dividida em onze municípios. Possui uma área total de 27.608,959 km² (IBGE, 2010).

Para a pesquisa, foram realizadas visitas as propriedades produtoras de ruminantes e equídeos em diferentes municípios da microrregião estudada, às agências de assistência aos produtores rurais (ADAPI e EMATER), e às Instituições de Ensino Superior e Técnico (CPCE/UFPI e CTBJ/UFPI). Onde foram entrevistadas 60 pessoas, usando como base o número de pessoas entrevistadas por Silva et al. (2006) em seu trabalho, sendo 48 produtores, 4 médicos veterinários, 4 técnicos agrícolas, 2 agrônomos e 2 zootecnistas, que residiam ou prestavam assistência técnica na microrregião. As entrevistas foram baseadas no preenchimento de formulários adaptados também do trabalho de Silva et al. (2006), associados ao uso de um catálogo simples contendo imagens e os nomes populares das principais plantas tóxicas de importância na pecuária da região Nordeste, totalizando assim, 33 imagens, também feitos a parte do formulário adaptado de Silva et al. (2006). Os participantes da pesquisa assinaram um termo de consentimento livre e esclarecido com as informações referentes ao trabalho.

O formulário aplicado foi composto por três partes. No formulário $\mathrm{n}^{\circ} 1$, constavam os nomes científicos e populares das plantas tóxicas da Região Nordeste encontrados no trabalho de Silva et al. (2006), além de perguntas subjetivas sobre a presença da planta na microrregião, sobre a caracterização da mesma como tendo potencial tóxico e o período do ano onde se observava o maior número de surtos. $\mathrm{O}$ formulário $\mathrm{n}^{\circ} 2$ teve caráter facultativo, onde o entrevistado, caso desejasse, destacaria alguma outra planta que não estava presente no formulário $\mathrm{n}^{\circ} 1$. Neste formulário se encontravam locais destinados às anotações referentes ao nome e aos sinais clínicos causados por plantas potencialmente tóxicas. Já o formulário $\mathrm{n}^{\circ} 3$, também de caráter facultativo, foi destinado a anotações de dados epidemiológicos sobre as suspeitas de surtos descritos pelo entrevistado.

As plantas tóxicas, de interesse pecuário, citadas durante a aplicação dos formulários, foram analisadas de maneira descritiva utilizando a Microsoft Excel 2007 e os dados apresentados foram discutidos utilizados os autores encontrados na literatura especializada.

\section{Resultados e discussão}

Todas as plantas listadas no formulário $\mathrm{n}^{\circ} 1$ do formulário aplicado, foram citadas pelo menos uma vez pelos entrevistados como existentes na microrregião do alto médio Gurguéia. Estando as plantas ranqueadas 
do maior para o menor valor com relação à quantidade de citações, seguindo assim a seguinte ordem: Manihot spp. 93,3\%, Brachiaria spp. 88,3\%, R. communis 88,3\%, E. contortisiliquum 85,0\%, I. sericophylla $85,0 \%$, M. tenuiflora $80,0 \%$, M. rigida $75 \%$, S. coriaceum $75,0 \%$, S. occidentalis $63,3 \%$, I. asarifolia $61,7 \%$, S. halepense $60 \%$, S. paniculatum 58,3\%, A. colubrina var. cebi 56,7\%, C. retusa 53,3\%, S. vulgare 51,7\% e T. glaucocarpa $50,0 \%$. Essas plantas se caracterizam como as mais significativas nesse aspecto, pois obtiveram valores iguais ou superiores a 50\%, o que corresponde a um número mínimo de 30 citações de uma população amostral avaliada de 60 indivíduos/entrevistados (Tabela 1).

Tabela 1. Plantas tóxicas existentes na Microrregião do Alto Médio Gurguéia

\begin{tabular}{|c|c|c|}
\hline Plantas & $\mathrm{n} / \mathrm{N}$ & $(\%)$ \\
\hline Manihot spp. (Macaxeira) & $56 / 60$ & 93,3 \\
\hline Brachiaria spp. (capim braquiária) & $53 / 60$ & 88,3 \\
\hline Ricinus communis (Mamona) & $53 / 60$ & 88,3 \\
\hline Enterolobium contortisiliquum (Tambor/tamboril) & $51 / 60$ & 85,0 \\
\hline Ipomoea sericophylla (Jetirana) & $51 / 60$ & 85,0 \\
\hline Mimosa tenuiflora (Jurema-preta) & $48 / 60$ & 80,0 \\
\hline Mascagnia rigida (Tinguí) & $45 / 60$ & 75,0 \\
\hline Stryphnodendron coriaceum (Barbatimão do NE) & $45 / 60$ & 75,0 \\
\hline Senna occidentalis (Mata pasto) & $38 / 60$ & 63,3 \\
\hline Ipomoea asarifolia (Salsa) & $37 / 60$ & 61,7 \\
\hline Sorghum halepense (Capim-de-boi) & $36 / 60$ & 60,0 \\
\hline Solanum paniculatum (Jurubeba) & $35 / 60$ & 58,3 \\
\hline Anadenanthera colubrina var. cebil (Angico-preto) & $34 / 60$ & 56,7 \\
\hline Crotalaria retusa (Chocalho de cobra) & $32 / 60$ & 53,3 \\
\hline Sorghum vulgare (Sorgo) & $31 / 60$ & 51,7 \\
\hline Thiloa glaucocarpa (Sipaúba) & $30 / 60$ & 50,0 \\
\hline Ipomoea carnea subsp. fistulosa (Algodão-bravo) & $27 / 60$ & 45,0 \\
\hline Amaranthus spp. (Bredo) & $27 / 60$ & 45,0 \\
\hline Aspidosperma pyrifolium (Pereiro) & $23 / 60$ & 38,3 \\
\hline Leucaena leucocephala (Leucena) & $19 / 60$ & 31,7 \\
\hline Centratherum punctatum (Perpétua) & $18 / 60$ & 30,0 \\
\hline Plumbago scandens (Louco) & $17 / 60$ & 28,3 \\
\hline Lantana camara (Chumbinho) & $15 / 60$ & 25,0 \\
\hline Froelichia humboldtiana (Ervanço) & $15 / 60$ & 25,0 \\
\hline Prosopis juliflora (Algaroba) & $14 / 60$ & 23,3 \\
\hline Palicourea spp. (Erva de rato/cafezinho, vick) & $12 / 60$ & 20,0 \\
\hline Tephrosia cinerea (Falso anil) & $11 / 60$ & 18,3 \\
\hline Cnidoscolus quercifolius (Favela) & $11 / 60$ & 18,3 \\
\hline Ipomoea riedelii (Anicão) & $10 / 60$ & 16,7 \\
\hline Nerium oleander (Espirradeira) & $06 / 60$ & 10,0 \\
\hline Marsdenia megalantha (Mata calado) & $02 / 60$ & 3,3 \\
\hline Indigofera suffruticosa (Anil) & $02 / 60$ & 3,3 \\
\hline Turbina cordata (Capoteira) & $01 / 60$ & 1,7 \\
\hline
\end{tabular}

n: número de vezes citada; N: número de plantas estudadas; \%: Frequência.

Ainda na tabela 1, pode-se perceber que as plantas com menor significância neste aspecto foram: $M$. megalantha, I. suffruticosa e T. cordata, pois obtiveram valores inferiores a $10 \%$, mais especificamente obtiveram valores respectivos de $3,3 \%, 3,3 \%$ e $1,7 \%$.

Resultados semelhantes foram relatados por Mello et al. (2010) em seu trabalho sobre o levantamento das plantas tóxicas de importância para ruminantes e equídeos encontradas no Norte do Estado do Piauí. Os resultados mostraram que plantas como A. pyrifolium, L. camara, P. juliflora e T. cinerea, entre outras, também citadas como existentes nos municípios pertencentes à microrregião estudada também 
foram citadas por alguns entrevistados como presentes na região Norte do Estado, mas sem o conhecimento da toxicidade das mesmas.

O ranqueamento das plantas mostradas na tabela 1 é de grande importância para se formar o perfil da flora da região, pois mesmo que a maioria das plantas mencionadas não seja caracterizada como tóxicas pelos produtores e profissionais que criam e atuam nos municípios pertencentes à microrregião. Há uma grande possibilidade de que as mesmas estejam sendo negligenciadas por estes indivíduos, que relacionam os casos de intoxicações dos animais de produção apenas a um grupo seleto de plantas (Tabela 2). Sendo que todas as plantas listadas na tabela 1 já possuem provas cientificas na literatura de seu potencial tóxico e da sua importância para a clínica médica destes animais, como foi mostrado por (Barbosa et al., 2007; Silva et al., 2006).

$\mathrm{Na}$ tabela 2 foi apresentado o ranqueamento das plantas que foram relacionadas com casos de intoxicações pelos entrevistados. Como forma de priorizar as plantas mais citadas pelos entrevistados discutiu-se apenas as plantas que tinham um número mínimo de 10 citações de uma população amostral de 60 indivíduos/entrevistados, o que corresponde a 16,7\%, visto que as demais plantas obtiveram citações mínimas ou não foram citadas por nenhum entrevistado neste quesito. Assim, as plantas caracterizadas como tóxicas pelos entrevistados neste trabalho foram: Manihot spp. 78,3\%, S. coriaceum $55 \%$, Brachiaria spp. 43,3\%, E. contortisiliquum 41,7\%, M. rigida 41,7\%, I. asarifolia 33,3\%, $R$. communis $25 \%$ e T. glaucocarpa $21,7 \%$. Resultados semelhantes foram encontrados por Magalhães et al. (2013), em trabalho realizado nos municípios pertencentes à microrregião do Cariri, localizada no vale do Cariri, Estado do Ceará. Plantas como I. asarifalia, E. contortisliquum, M. rigida e Manihot spp., receberam um grande número de citações, sendo caracterizadas assim, como tóxicas na região e possuindo relevância significativa na clínica de ruminantes e equídeos da região Norte do Estado do Ceará. I. asarifolia, R. communis, S. coriaceum e T. glaucocarpa (Sipaúba) também foram tidas como plantas de importância na clínica de intoxicações de animais ruminantes e equídeos no Norte do Estado do Piauí (Mello et al., 2010).

Tabela 2. Plantas caracterizadas como tóxicas pelos entrevistados na Microrregião do Alto Médio Gurguéia

\begin{tabular}{lcc}
\hline Plantas & $\mathrm{n} / \mathrm{N}$ & $(\%)$ \\
\hline Manihot spp. (Macaxeira) & $47 / 60$ & 78,3 \\
S. coriaceum (Barbatimão do NE) & $33 / 60$ & 55,0 \\
Brachiaria spp. (Capim braquiária) & $26 / 60$ & 43,3 \\
E. contortisiliquum (Tambor/tamboril) & $25 / 60$ & 41,7 \\
M. rigida (Tinguí) & $25 / 60$ & 41,7 \\
I. asarifolia (Salsa) & $20 / 60$ & 33,3 \\
R. communis (Mamona) & $15 / 60$ & 25,0 \\
T. glaucocarpa (Sipaúba) & $13 / 60$ & 21,7 \\
\hline
\end{tabular}

n: número de vezes citada; N: número de plantas estudadas; \%: Frequência.

Outro fator que deve ser destacado com relação ao número reduzido de plantas que são associadas à casuística de intoxicações na microrregião do Alto Médio Gurguéia é a falta de conhecimento técnico sobre o assunto e a ausência de assistência profissional aos produtores da região, pois a maioria dos entrevistados apenas entende como intoxicação, aqueles que chegam a óbito por morte súbita sem diagnostico preciso, como pode ser visto na tabela 4.

Algumas plantas foram destacadas pelos entrevistados como tendo potencial tóxico e apresentando certa casuística nos municípios pertencentes à microrregião e que não estavam presentes no formulário $\mathrm{n}^{\circ} 1$. Neste contexto, as mais citadas foram: M. pseudoglaziovii 25,0\%,D. mollisBenth 14,3\%, M. indica $7,1 \%$ e D. ecastophyllum 7,1\% (Tabela 3).

Segundo Magalhães et al. (2013) a M. pseudoglaziovii já é mostrada na literatura como tendo importância na clínica de animais de produção na região Nordeste. O autor afirma que tal planta apresenta efeito cianogênico sobre o animal, pois possui em sua estrutura glicosídeos cianogênicos que, se ingeridos em grandes proporções, liberam uma quantidade considerável de cianeto após a mastigação 
que por meio de hidrólise formam ácido cianídrico $(\mathrm{HCN})$, o que causa a morte do animal devido a uma anóxia generalizada em consequência da inibição da respiração celular pelo HCN.

A D. mollisBenth apresenta toxicidade elevada quando suas vargens são consumidas por bovinos em quantidade igual ou superior a 25 gramas por peso vivo de uma só vez. Os sinais clínicos mais observados em bovinos são diminuição do apetite, emagrecimento progressivo, pelos arrepiados; fezes de consistência pastosa até semilíquida e de coloração amarelada, com muco e estrias ou mesmo coágulos de sangue. Já com relação aos achados de necropsia, observam-se edemas no tecido subcutâneo; presença de líquido claro nas cavidades torácica e abdominal; edema do mesentério, hemorragias no trato digestivo, principalmente ceco e intestino grosso; rins com pequenos e nítidos pontos vermelhos na superfície e friável ao corte (Tokarnia \& Döbereiner, 2000; Tokarnia \& Dobereiner, 1979).

Tabela 3. Plantas citadas pelos produtores como tóxicas na Microrregião que não estavam listadas no Formulário

\begin{tabular}{lcc}
\hline Plantas & $\mathrm{n} / \mathrm{N}$ & $\%$ \\
\hline Manihot pseudoglaziovii (Maniçoba) & $7 / 28$ & 25 \\
Dimorphandra mollisBenth (Faveiro/Falso Barbatimão) & $4 / 28$ & 14,3 \\
Mangifera indica (Manga)* & $2 / 28$ & 7,1 \\
Dalbergia ecastophyllum (Bugí/Rabo-de-Bugí) & $2 / 28$ & 7,1 \\
Hybanthus calceolaria (Papaconha) & $01 / 28$ & 3,6 \\
Marsypianthes chamaedrys (Vahl) Kuntze (Betonca/Betônica) & $01 / 28$ & 3,6 \\
Eugenia dysenterica Myrtaceae (Cagaita) & $01 / 28$ & 3,6 \\
Cordia ecalyculata (Cafezinho de Goiás/Claraíba) & $01 / 28$ & 3,6 \\
Dioclea grandiflora Mart (Mucunã) & $01 / 28$ & 3,6 \\
Psidium appendiculatum (Araça) & $01 / 28$ & 3,6 \\
Caesalpinia pyramidalisTul. (Pau-de-rato) & $01 / 28$ & 3,6 \\
Jatropha gossypiifolia (Pinhão bravo/Pião brabo) & $01 / 28$ & 3,6 \\
Genipa americana L. (Jenipapo** & $01 / 28$ & 3,6 \\
Mimosa pudica L. (Maliça-de-boi/Malícia/Dormideira) & $01 / 28$ & 3,6 \\
Richardia grandiflora (Rama-de-sapo/Baba-de-sapo) & $01 / 28$ & 3,6 \\
Pteridium aquilinum (Samambaia/Samambaia-do-campo) & $01 / 28$ & 3,6 \\
Cnidoscolus urens (Cansanção) & $01 / 28$ & 3,6 \\
\hline Total & 28 & 100
\end{tabular}

n: número de vezes citada; $\mathbf{N}$ : número de plantas estudadas; \%: Frequência; ${ }^{(*)}$ fruto.

Há uma peculiaridade nos casos de intoxicação com $M$. indica, pois os indivíduos que a citaram como tóxica, também afirmaram que os bovinos que apresentaram sinais clínicos de intoxicação pelo seu consumo eram apenas aquele que consumiram o fruto após longos dias ao chão, onde já era possível se observar o aparecimento de colônias de micro-organismos. E isso é confirmado por Assis et al. (2009) que afirmam que os frutos de $M$. indicam são responsabilizados por causarem intoxicação etílica em animais de produção como os ruminantes, quando estão a muito tempo ao solo e são fermentadas pela ação de micro-organismos, produzindo substancias etanólicas.

Em relação a D. ecastophyllum não foram encontrados trabalhos que relacionem esta planta a casos de intoxicações em animais de produção. Há relato apenas da utilização de própolis de coloração vermelha oriundas desta planta na alimentação de ruminantes. Neste trabalho o autor aponta que a própolis, oriundo da resina da $D$. ecastophyllum, apresenta efeito citotóxico devido à presença de flavonoides (Ghisalberti, 1979; Sforcin, 2007; Vecchi \& Drago, 2007).

Como pode ser observado na tabela 4, M. pseudoglaziovii foi responsável por três surtos de intoxicação em municípios da microrregião. O primeiro surto relatado refere-se ao ano de 2012 , no município de Palmeira do Piauí, onde aproximadamente 100 bovinos de várias idades e ambos os sexos vieram a óbito pelo consumo desta planta. O segundo surto, aconteceu na localidade do Assentamento Rio preto, Município de Bom Jesus no ano de 2016. Nesse surto seis bovinos de diferentes idades e de ambos os sexos vieram a óbito de forma súbita, sendo estas mortes também relacionadas ao consumo 
de M. pseudoglaziovii na forma in natura. Já o terceiro surto ocorreu no ano de 2017, na localidade de Buritizal, Município de Currais. Neste caso específico, três bovinos vieram a óbito pelo consumo de $M$. pseudoglaziovii e $M$. rigida. Silva et al. (2006) também relatou casos de intoxicação por esta planta, onde 75 bovinos adoeceram e três animais vieram a óbito pelo consumo de M. pseudoglaziovii no Estado do Rio Grande do Norte.

Outra planta que, segundo o relato de um entrevistado, provoca grandes prejuízos no município de Bom Jesus é a P. juliflora. Segundo relatos dos entrevistados, esta planta no início do ano de 2017, matou cerca de 50 ovinos e caprinos. Silva et al. (2006) também afirmam que nas secas de 1993 e 1994, de 170 ruminantes, adoeceram 65 e morreram 60 pelo consumo de $P$. juliflora.

E. contortisiliquum também foi causador de um surto que desencadeou aborto em aproximadamente 50 fêmeas bovinas na localidade de Gruta Bela, Bom Jesus. Sendo que no município do Crato, Ceará também foi relatado abortos (cerca de seis por ano) em fêmeas bovinas pelo consumo dessa planta, além de fotossensibilização em indivíduos de ambos os sexos e várias idades (Haraguchi, 2003; Mello et al., 2010; Silva et al., 2006).

A S. coriaceum é destacado como sendo o causador de três surtos em dois municípios da microrregião. O primeiro surto caracterizou-se por casos de fotossensibilização e morte de 50 bovinos na localidade de Terçado, Currais. O segundo surto aconteceu na localidade de São Francisco, município de Palmeira do Piaú, aonde 12 bovinos vieram a óbito pelo consumo desta planta. E o terceiro surto ocorreu na localidade de Bamal, também no município de Palmeira do Piauí, onde quatro bovinos morreram pelo consumo desta planta. Mello et al. (2010) também relataram a morte de dois a cinco bovinos por ano por causa do consumo da fava do barbatimão no Norte do Estado do Piauí.

Tabela 4. Surtos relatados pelos entrevistados nas cidades pertencentes à Microrregião do Alto Médio Gurguéia

\begin{tabular}{|c|c|c|c|c|c|c|}
\hline $\begin{array}{l}\text { Quantidad } \\
\text { e animais }\end{array}$ & Espécie & Tipo de injúria & $\begin{array}{c}\text { Ano de } \\
\text { ocorrência }\end{array}$ & Planta & Local & Município \\
\hline 100 & Bovino & Morte & 2014 & M. pseudoglaziovii (Maniçoba) & Centro & Palmeira do Piauí \\
\hline 50 & $\begin{array}{l}\text { Ovino e } \\
\text { Caprino }\end{array}$ & Morte & 2017 & P. juliflora (Algaroba) & Toda Região & Bom Jesus \\
\hline 50 & Bovino & Aborto & 2015 & E. contortisiliquum (Tamboril) & Gruta Bela & Bom Jesus \\
\hline 50 & Bovino & $\begin{array}{l}\text { Fotossensibilização } \\
\text { e Morte }\end{array}$ & 2017 & S. coriaceum (Barbatimão) & Terçado & Currais \\
\hline 20 & Bovino & Morte & 2015 & $\begin{array}{l}\text { T. glaucocarpa (Simpauba) e } A \text {. } \\
\text { colubrina var. cebil (Angico Preto) }\end{array}$ & Centro & Bom Jesus \\
\hline 12 & Bovino & Morte & 2007 a 2017 & S. coriaceum (Barbatimão) & São Francisco & Palmeira do Piauí \\
\hline 10 & Bovino & Morte & 2015 & C. ecalyculata (Cafezinho De Goiás) & Correntinha & Currais \\
\hline 10 & Bovino & Morte & 2016 & $\begin{array}{l}\text { T. glaucocarpa (Simpauba) e } C \text {. } \\
\text { pyramidalisTul. (Pau-De-Rato) }\end{array}$ & Larges & Santa Luz \\
\hline 08 & Bovino & Morte & 2017 & M. rígida (Tinguí) & Centro & Santa Luz \\
\hline 06 & Bovino & Morte & 2016 & M. pseudoglaziovii (Maniçoba) & As. Rio Preto & Bom Jesus \\
\hline 05 & Bovino & Aborto & 2010 a 2017 & M. rígida (Tinguí) & Centro & Bom Jesus \\
\hline 05 & Bovino & Morte & 2010 & M. indica (Manga) & Cupins & Redenção do Gurgéic \\
\hline 04 & Bovino & Morte & 2016 & S. coriaceum (Barbatimão) & Bamal & Palmeira do Piauí \\
\hline 04 & Bovino & Morte & 2017 & M. rígida (Tinguí) & Buritizal & Currais \\
\hline 03 & Bovino & Morte & 2017 & $\begin{array}{c}\text { M. pseudoglaziovii (Maniçoba) E } M . \\
\text { rígida (Tinguí) }\end{array}$ & Buritizal & Currais \\
\hline 03 & Equino & Morte & 2014 & Brachiaria spp. (Capim braquiária) & Centro & Bom Jesus \\
\hline 03 & Bovino & Morte & 2015 & M. rígida (Tinguí) & Fazenda Riacho & Bom Jesus \\
\hline 02 & Bovino & Morte & 2014 & Manihot spp. (Macaxeira) & Centro & Palmeira do Piauí \\
\hline
\end{tabular}

A T. glaucocarpa foi responsável por dois surtos na região, mas sempre está associado à outra planta, como é o caso do A. colubrina var. cebil e do $C$. pyramidalisTul. No primeiro surto, a $T$. glaucocarpa juntamente com a A. colubrina var. cebil causaram a morte de 20 bovinos na cidade de Bom Jesus no ano de 2015. Já no ano de 2016, a mesma planta junto ao C. pyramidalisTul., causaram a morte de 10 bovinos, na localidade de Largem, município de Santa Luz. A plantadenominada C. ecalyculata foi responsável pela morte de 10 bovinos, no ano de 2015, na localidade de Correntinha, Currais.

Já a $M$. rígida é responsável pelo surto já destacado anteriormente e mais quatro surtos em três municípios diferentes. Em Santa Luz, no ano de 2017, oito bovinos vieram a óbito pelo consumo desta 
planta, já em Bom Jesus, segundo o relato de um dos entrevistados, cinco bovinos morreram entre os anos de 2010 a 2017 também pelo consumo de água contaminada devido ao uso desta planta em pesca nos rios e riachos da região. E na localidade da Fazenda Riacho, no município de Bom Jesus, no ano de 2015, três bovinos morreram. Durante as entrevistas, os entrevistados usavam comumente o termo "tinguizado" para definir animais que apresentavam sinais clínicos de intoxicação por Tinguí. Casos de intoxicação pelo consumo desta planta em bovinos e ovinos também foram relatados (Haraguchi, 2003; Mello et al., 2010; Silva et al., 2006).

Neste contexto, plantas como a M. indica, Brachiaria spp. e Manihot spp. também foram destacadas como responsáveis de surtos em bovinos e equinos na região. A $M$. indica foi dada como responsável pela morte de cinco bovinos na localidade de Cupins, Redenção no ano de 2010. Já A Brachiariaspp foi definida por um dos entrevistados como sendo o causador da morte de três equinos no município de Bom Jesus, no ano de 2014. E a Manihot spp. foi também relacionada à morte de dois bovinos no ano de 2014 no município de Palmeira do Piauí. Segundo Mello et al. (2010) a Manihot spp. foi responsável por intoxicar 15 vacas de um rebanho leiteiro de 150 animais, onde sete morreram em uma propriedade no Norte do Estado do Piauí.

Com relação aos sinais clínicos citados pelos entrevistados, como sendo característicos dos casos de intoxicação por plantas (Tabela 5), destacam-se aqueles causados pela planta denominada $C$. pyramidalis Tul., que, segundo os entrevistados, provoca nos animais que a ingerem, edema na região dos membros e pescoço, problemas intestinais e afeta o sistema nervoso, causando situações de estresse agudo. Segundo Bahia et al. (2005) e Chaves et al. (2019) esta planta apresenta vários metabolitos secundários, onde se destacam os polifenóis, como é o caso de taninos e terpenóides. Todavia, os autores não associam os casos de intoxicação a estes metabolitos, também não há relatos de outros casos de intoxicação pelo consumo desta planta.

Tabela 5. Sinais clínicos de intoxicação citados pelos entrevistados

\begin{tabular}{|c|c|}
\hline Plantas & Sinais clínicos em ruminantes \\
\hline C. pyramidalis Tul. (Pau-de-rato) & $\begin{array}{l}\text { Edema de membros e pescoço; Problemas intestinais; Prostração em } \\
\text { situações de estresse agudo }\end{array}$ \\
\hline M. pseudoglaziovii (Maniçoba) & $\begin{array}{l}\text { Em Bovinos: Vertigem; Decúbito; Movimentos de pedalada. Oligúria; } \\
\text { Prostração em situações de estresse agudo; Timpanismo } \\
\text { Em Ovinos e Caprinos: Retenção placentária; Aborto; Diarreia }\end{array}$ \\
\hline C. aecalyculata (Cafezinho de Goiás/Claraíba) & Morte Súbita \\
\hline D. ecastophyllum (Bugí/Rabo-de-Bugí) & Aborto; Decúbito; Destruição da mucosa intestinal \\
\hline R. grandiflora (Rama-de-sapo/Baba-de-sapo) & Vertigem; Aborto \\
\hline D. grandiflora Mart (Mucunã) & Diarreia; Timpanismo \\
\hline D. mollis Benth (Faveiro/Falso Barbatimão) & Anúria; Anorexia; Febre; Fotossensibilização \\
\hline M. pudica L. (Maliça-de-boi/Malícia/Dormideira) & Decúbito \\
\hline M. chamaedrys (Vahl) Kuntze (Betonca/ Betônica) & Diarreia \\
\hline E. dysenterica Myrtaceae (Cagaita) & Diarreia \\
\hline P. aquilinum (Samambaia/Samambaia-do-campo) & Epistaxe \\
\hline G. americana L. (Jenipapo) & Vertigem; Decúbito \\
\hline M. indica (Manga) & Alopecia; Morte súbita \\
\hline P. appendiculatum (Araça) & Fotossensibilização \\
\hline M. rigida (Tinguí) & Diarreia; Poliúria \\
\hline S. coriaceum (Barbatimão do NE) & Fotossensibilização; Timpanismo; Constipação \\
\hline
\end{tabular}

Destaca-se também a M. pseudoglaziovii, que segundo os entrevistados apresenta uma série de sinais clínicos tanto em bovinos como em pequenos ruminantes. Nos bovinos, esta planta provoca vertigem, decúbito, movimentos de pedalada, oligúria, aumento da região ruminal, além de afetar o sistema nervoso. Já em ovinos e caprinos, percebe-se retenção de placenta, aborto e diarreia. Os sinais clínicos relatados são compatíveis com a maioria dos sinais clínicos destacado por Caldas et al. (2005) e Sant'Ana et al. (2014), onde foram observados tremores musculares, descoordenação, salivação, mucosas cianóticas, dilatação da 
pupila, opistótono, decúbito esternal, movimentos de pedalagem e convulsões em animais que consumiram essa planta.

A planta denominada D. ecastophyllumm, segundo o relato dos entrevistados, apresenta sintomatologia relacionada, principalmente, ao sistema reprodutor e intestinal, pois causa abortos nas fêmeas bovinas, além de causar a destruição da mucosa intestinal, o que leva o animal a entrar em decúbito e em casos graves, a morte.

Também com efeitos no sistema reprodutor observa-se a $R$. grandiflora, essa planta causa em fêmeas bovinas prenhes, se consumida em grandes quantidades, vertigem e em casos mais graves, como foi relatado pelos entrevistados, causa também aborto.

Com efeito, sobre o sistema digestório, a $D$. Grandiflora Mart causa nos animais ruminantes que a consomem, diarreia e aumento da região ruminal. Efeitos parecidos são observados pelo consumo de $M$. chamaedrys (Vahl) Kuntze e E. dysenterica Myrtaceae que provocam diarreia na maioria das vezes aquosa nos animais ruminantes, e a $M$. rigida que além de causar diarreia nos animais, provoca também poliúria, o que pode levar o animal a uma desidratação acentuada e a morte. No entanto, ao se confrontar esses sinais clínicos com os destacados para essa planta por Barbosa et al. (2007), percebe-se uma disparidade entre os resultados, pois o autor destaca como sendo sinal clínico da intoxicação por $M$. rígida, decúbito esterno abdominal, depressão, instabilidade, descoordenação, tremores musculares, entre outros.

Com relação a plantas que causam fotossensibilização destacam-se neste contexto $P$. Appendiculatum, D. mollisBenth e $S$. coriaceum. Sendo que a $D$. mollisBenth causa, ainda, anúria, anorexia e febre. A $S$. coriaceum ainda provoca aumento da região ruminal e constipação (Tabela 5). Segundo Magalhães et al. (2013) a S. coriaceum possui em sua estrutura uma grande quantidade de tanino. Haraguchi (2003) acrescenta, ainda, que o consumo desta planta causa apatia, ressecamento do focinho, anorexia, parada da ruminação, tremores musculares, salivação e lacrimejamento.

Ainda em referência à $S$. coriaceum, três entrevistados relataram que o óbito pelo consumo desta planta pelos bovinos se dá por causa da germinação das sementes dentro das divisões intestinais destes animais, o que provoca obstrução do trato digestório, levando, em alguns casos, o animal a morte. No entanto, não foi encontrado na literatura nenhum relato semelhante ou informações científicas que comprovem a veracidade deste fato.

Segundo relatos, o consumo dos frutos das plantas denominadas G. americanaL. e M. indica, provocam nos animais sinais clínicos que vão desde vertigem e decúbito, alopecia e em casos graves, morte de forma súbita. Já a planta denominada $C$. ecalyculata, leva o animal a uma morte súbita e rápida, sem a apresentação de outros sinais clínicos.

Dentre as plantas que foram citadas pelos entrevistados, mas que não apresentavam mais riquezas de detalhes neste quesito se encontra a $M$. pudica L., que segundo relato dos entrevistados, percebe-se no animal apenas decúbito lateral. E a P. aquilinum que, segundo relatos (Marçal et al., 2001; Oliveira et al., 1998) provoca apenas sangramento nasal no animal.

\section{Conclusões}

Pode-se concluir que as plantas com potencial tóxico na microrregião do Alto Médio Gurguéia são: Manihot spp. 78,3\%, S. coriaceum 55,0\%, Brachiaria spp. 43,3\%, E. contortisiliquum 41,7\%, M. rigida 41,7\%, I. asarifolia 33,3\%, R. communis 25,0\%, T. glaucocarpa 21,7\%, M. pseudoglaziovii 25\%, D. mollisBenth 14,3\%, M. indica 7,1\% e D. ecastophyllum 7,1\%. Como forma de continuação do trabalho, pretende-se realizar um projeto de extensão rural, com o intuito de transferir o conhecimento adquirido com este trabalho para os produtores e profissionais da área que criam e atuam nos municípios pertencentes à microrregião do alto médio Gurguéia. Além de publicar os resultados obtidos neste trabalho em revistas de cunho científico.

\section{Referências bibliográficas}

ABIEC. (2019). Associação Brasileira das Indústrias Exportadoras de Carnes. Exportações Brasileiras de Carne Bovina-Brazilian Beef Exports. Brasília, Brasil: Governo brasileiro. 
ADAPI - Agência de Defesa Agropecuária do Estado do Piauí. (2012). Projeto Educativo - Conhecendo a Febre Aftosa. Disponível em:〈http://www.adapi.pi.gov.br/doc/conhecendo_a_febre_aftosa.doc $>$. Acessado em: 13 de maio de 2018.

ANUALPEC. (2019). Anuário da Pecuária Brasileira (20th ed. Vol. 1). São Paulo, São Paulo, Brasil: Instituto FNP.

Assis, T. S., Medeiros, R. M. T., Araújo, J. A. S., Dantas, A. F. M. \& Riet-Correa, F. (2009). Intoxicações por plantas em ruminantes e equídeos no Sertão Paraibano. Pesquisa Veterinária Brasileira, 29(11):919-924.

Bahia, M. V., Santos, J. B., David, J. P. \& David, J. M. (2005). Biflavonoids and other phenolics from Caesalpinia pyramidalis (Fabaceae). Journal of the Brazilian Chemical Society, 16(6B):1402-1405. doi: http://dx.doi.org/10.1590/S0103-50532005000800017.

Barbosa, R. R., Silva, I. P., Ribeiro Filho, M. R. \& Soto-Blanco, B. (2007). Plantas tóxicas de interesse pecuário: importância e formas de estudo. Acta Veterinaria Brasilica, 1(1):1-7.

Caldas, S. A., Gabriel, A. M. A., Amorim, A. \& Conceição, J. H. S. (2005). Intoxicação de bovinos por plantas no médio Paraíba, RJ. Revista Brasileira de Medicina Veterinária, 27(2):27-30.

Chaves, T. P., Medeiros, F. D., Sousa, J. M. C., Silva, L. A. P., Lima, M. A., Coutinho, H. D. M. \& Medeiros, A. C. D. (2019). Phytochemical characterization and mutagenicity, cytotoxicity, antimicrobial and modulatory activities of Poincianella pyramidalis (Tul.) LP Queiroz. Natural Product Research1-6. doi: http://dx.doi.org/10.1080/14786419.2019.1566724

Ghisalberti, E. (1979). Propolis: a review. Bee World, 6059-84.

Haraguchi, M. (2003). Plantas tóxicas de interesse na pecuária. São Paulo.

Magalhães, R. M. F., Carneiro, M. S. S. \& Sales, R. O. (2013). Plantas tóxicas de interesse pecuário encontradas na região nordeste do Brasil: Uma Revisão. Revista Brasileira de Higiene e Sanidade Animal, 7(1):79-102.

Marçal, W. S., Gaste, L., Netto, N. C. R., Marques, M. C. G., Fernandes, R. P. \& Monteiro, A. A. (2001). Ocorrência de intoxicação aguda em bovinos pela samambaia (Pteridium aquilinum, L. Kuhn) no norte do Paraná-Brasil. Semina: Ciências Agrárias, 22(2):139-144.

Mello, G. W. S., Oliveira, D. M., Carvalho, C. J. S., Pires, L. V., Costa, F. A. L., Riet-Correa, F. \& Silva, S. M. M. (2010). Plantas tóxicas para ruminantes e equídeos no Norte Piauiense. Pesquisa Veterinária Brasileira, 30(1):1-9.

Oliveira, G., Matsumoto, T. \& Primavesi, A. (1998). Ocorrência de intoxicação causada por samambaia (Pteridium aquilinum) na Região nordeste do Paraná. Embrapa-Comunicado Técnico, 201-9.

Sant'Ana, F. J. F., Reis Junior, J. L., Freitas Neto, A. P., Moreira Junior, C. A., Vulcani, V. A. S., Rabelo, R. E. \& Terra, J. P. (2014). Plantas tóxicas para ruminantes do Sudoeste de Goiás. Ciência Rural, 44(5):865-871.

Sforcin, J. M. (2007). Propolis and the immune system: a review. Journal of Ethnopharmacology, 113(1):1-14. doi: http://dx.doi.org/10.1016/j.jep.2007.05.012.

Silva, D. M., Riet-Correa, F., Medeiros, R. M. \& Oliveira, O. F. (2006). Plantas tóxicas para ruminantes e equíídeos no Seridó Ocidental e Oriental do Rio Grande do Norte. Pesquisa Veterinária Brasileira, 26(4):223-236.

Sousa, M. A. N., Lima Nóbrega, E., Melo, N. J. A. \& Silva Filho, E. F. (2014). Intoxicações naturais e experimentais em Aspidosperma pyrifolium Mart.(pereiro). Revista Saúde \& Ciência Online, 3(3):229-239.

Tokarnia, C. H. \& Döbereiner, J. (2000). Plantas tóxicas do Brasil. Rio de Janeiro, Brasil: Helianthus.

Tokarnia, C. H. \& Dobereiner, J. S. (1979). Plantas tóxicas da Amazonia a bovinos e outros herbívoros (Vol. 1, pp. 1-95). Manaus, Amazonas: Instituto de Pesquisas da Amazônia,.

Vecchi, E. \& Drago, L. (2007). Propolis' antimicrobial activity: what's new? Infez Med, 15(1):7-15.

Recebido: 25de agosto, 2019.

Aprovado: 6 de novembro, 2019

Publicado: 25 de janeiro, 2020.
Licenciamento: Este artigo é publicado na modalidade Acesso Aberto sob a licença Creative Commons Atribuição 4.0 (CC-BY 4.0), a qual permite uso irrestrito, distribuição, reprodução em qualquer meio, desde que o autor e a fonte sejam devidamente creditados 